\title{
Christoph Herrmann
}

\section{Währungshoheit, Währungsverfassung und subjektive Rechte}

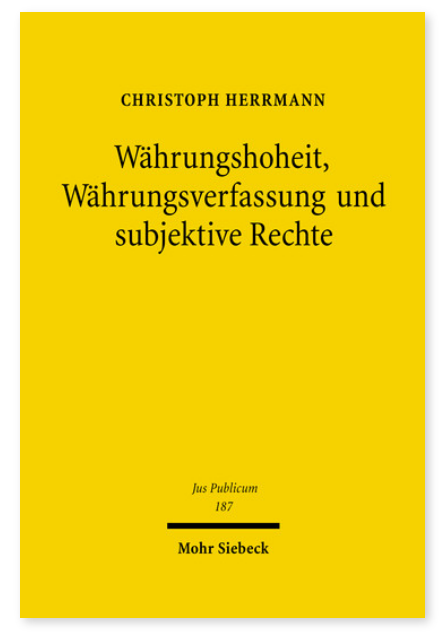

2010. XXX, 473 Seiten. JusPubl 187

ISBN 978-3-16-151268-1

DOI 10.1628/978-3-16-151268-1

eBook PDF 139,00 €

ISBN 978-3-16-150008-4

Leinen $139,00 €$
»Geld ist geprägte Freiheit« heißt es; es spielt also für die Lebenswirklichkeit von Menschen in einer arbeitsteiligen Wirtschaft eine zentrale Rolle. Ungeachtet dieses offenkundigen Bezugs des Geldes zur Freiheitsentfaltung von Individuen wird Geld dennoch nahezu ausnahmslos im Rahmen einer staatlichen oder auch supranationalen rechtlichen Zwangsordnung bereitgestellt, die dem Staat beziehungsweise der Europäischen Gemeinschaft das Währungsmonopol sichert. Zugleich wird die Freiheit von Individuen im Umgang mit Geld rechtlich erheblich beschränkt, während eine individualrechtliche Gewähr seines Werterhalts vom Staat jedoch nicht übernommen wird. Ausgehend von diesen Problemen unterzieht Christoph Herrmann in diesem Buch die geltende Währungsverfassung vor dem Hintergrund der interdisziplinären Grundlagen des Geldwesens einer subjektivrechtlichen Überprüfung und Rekonstruktion.

Christoph Herrmann Geboren 1973; Studium der Rechtswissenschaft in Bayreuth und London; 2002 Promotion; 2009 Habilitation; Inhaber des Lehrstuhls für Staats- und Verwaltungsrecht, Europarecht, Europäisches und Internationales Wirtschaftsrecht an der Universität Passau.

Jetzt bestellen:

https://mohrsiebeck.com/buch/waehrungshoheit-waehrungsverfassung-und-subjektive-rechte-9783161512681?no_cache=1 order@mohrsiebeck.com

Telefon: +49 (0)7071-923-17

Telefax: +49(0)7071-51104 